CLINICAL STUDY

\title{
Is pituitary TSH an adequate measure of thyroid hormone- controlled homoeostasis during thyroxine treatment?
}

\author{
Rudolf Hoermann, John E M Midgley ${ }^{1}$, Rolf Larisch and Johannes W Dietrich ${ }^{2}$ \\ Department of Nuclear Medicine, Klinikum Luedenscheid, Paulmannshoeher Street 14, D-58515 Luedenscheid, Germany, ${ }^{1}$ North Lakes Clinical, 6 High \\ Wheatley, Ilkley LS29 8RX, UK and ${ }^{2}$ Medizinische Klinik I, Endokrinologie und Diabetologie, BG Universitätsklinikum Bergmannsheil GmbH, Ruhr \\ University of Bochum, Buerkle-de-la-Camp-Platz 1, D-44789 Bochum, Germany \\ (Correspondence should be addressed to R Hoermann; Email: rudolf.hoermann@gmail.com)
}

\begin{abstract}
Objective: In recognition of its primary role in pituitary-thyroid feedback, TSH determination has become a key parameter for clinical decision-making. This study examines the value of TSH as a measure of thyroid hormone homoeostasis under thyroxine $\left(\mathrm{T}_{4}\right)$ therapy.

Design and methods: We have examined the interrelationships between free triiodothyronine $\left(\mathrm{FT}_{3}\right)$, free $\mathrm{T}_{4}\left(\mathrm{FT}_{4}\right)$ and pituitary TSH by means of $\mathrm{i}$ ) a retrospective analysis of a large clinical sample comprising 1994 patients either untreated or on varying doses of $\mathrm{L}_{-} \mathrm{T}_{4}$ and ii) independent mathematical simulation applying a model of thyroid homoeostasis, together with a sensitivity analysis.

Results: Over a euthyroid to mildly hyperthyroid functional range, we found markedly different correlation slopes of $\log$ TSH vs $\mathrm{FT}_{3}$ and $\mathrm{FT}_{4}$ between untreated patients and $\mathrm{L}_{-} \mathrm{T}_{4}$ groups. Total deiodinase activity $\left(\mathrm{G}_{\mathrm{D}}\right)$ was positively correlated with TSH in untreated subjects. However, $\mathrm{G}_{\mathrm{D}}$ was significantly altered and the correlation was lost under increasing $\mathrm{L}_{-} \mathrm{T}_{4}$ doses. Ninety-five per cent confidence intervals for $\mathrm{FT}_{3}$ and $\mathrm{FT}_{4}$, when assessed in defined $\mathrm{TSH}$ concentration bands, differed significantly for $\mathrm{L}_{-} \mathrm{T}_{4}$-treated compared with untreated patients. Higher doses were often needed to restore $\mathrm{FT}_{3}$ levels within its reference range. Sensitivity analysis revealed the influence of various structural parameters on pituitary TSH secretion including an important role of pituitary deiodinase type 2 .

Conclusion: The data reveal disjoints between $\mathrm{FT}_{4}-\mathrm{TSH}$ feedback and $\mathrm{T}_{3}$ production that persist even when sufficient $\mathrm{T}_{4}$ apparently restores euthyroidism. $\mathrm{T}_{4}$ treatment displays a compensatory adaptation but does not completely re-enact normal euthyroid physiology. This invites a study of the clinical consequences of this disparity.
\end{abstract}

European Journal of Endocrinology 168 271-280

\section{Introduction}

Thyrotoxicosis and hypothyroidism have been traditionally defined as states where elevated or decreased concentrations of circulating free thyroid hormones exert their own appropriate influences on the numerous metabolic outputs and organ functions of the body (1). Cellular access to triiodothyronine $\left(\mathrm{T}_{3}\right)$ is tightly controlled by two mechanisms, an active transport into the cell and an enzymatic conversion of thyroxine $\left(\mathrm{T}_{4}\right)$ to $\mathrm{T}_{3}$ by deiodinases, which exist in different subtypes $(2,3)$. Conversion is also the main source of $\mathrm{T}_{3}$ in humans, making up about $80 \%$ of its production, the rest being directly supplied by the thyroid gland (4). Failure of the thyroid gland or any change in hormone production is sensitively reflected at the pituitary level via a negative feedback within the hypothalamuspituitary-thyroid regulatory loop. As a result, statistically derived TSH reference ranges have shaped definitions of thyroid dysfunctions, introducing subclinical disease entities and thus have been given the various roles of screening tool, therapeutic target and prognostic marker $(5,6,7,8,9)$.

The TSH-centred definition of thyroid function has both merits and disadvantages. While TSH has become accurately and readily measurable, the exact reference values remain elusive $(5,10,11,12)$. Moreover, in an individual, normal distribution of thyroid hormone concentrations encompasses only a fraction of the span of the population reference range and the TSH set point is particularly tightly controlled (13).

On the other hand, appreciation of the interplay of $\mathrm{TSH}$, free $\mathrm{T}_{3}\left(\mathrm{FT}_{3}\right)$ and free $\mathrm{T}_{4}\left(\mathrm{FT}_{4}\right)$ should facilitate a more individualised approach than relating analytic decisions to the broad inter-individual variation of each parameter. This concept requires a clear understanding of the interaction of these parameters under various physiological and pathophysiological conditions, in particular the implications of their homoeostatically controlled equilibria.

We have therefore sought to assess the interrelation of $\mathrm{FT}_{3}, \mathrm{FT}_{4}$ and pituitary TSH, querying reliance on TSH 
as a reliable measure for thyroid hormone homoeostasis under $\mathrm{T}_{4}$ therapy. To this end, we i) retrospectively analysed a broad clinical sample and ii) tested our conclusions by a mathematical simulation.

\section{Materials and methods}

\section{Patients and laboratory samples}

This study extends an earlier publication where full details of methods were described (14). Data were obtained from a large number of unselected patients referred for thyroid testing to the Departments of Endocrinology or Nuclear Medicine of the Klinikum Ludenscheid, Germany, between October 2006 and January 2007. Excluded from analysis were patients with pituitary or hypothalamic disorders, critically ill patients, patients with renal failure and pregnant women, as those conditions can interfere unpredictably with thyroid testing.

The focus of this study was on treatment-related aspects of the thyroid-pituitary relationship. To this end, 1994 patients and as many samples (including only the first sample per patient) were included for analysis. Of them, 1159 patients were untreated, receiving neither thyroid medication nor any other drugs at the time of sampling. Others were on levo $\mathrm{T}_{4}(\mathrm{~L}-$ $\mathrm{T}_{4}$ ) or iodine in varying doses of $50-200 \mu \mathrm{g} /$ day $(n=785)$ or 100 or $200 \mu \mathrm{g} /$ day $(n=50)$ respectively. The small group of iodine-treated patients was deliberately separated from untreated subjects to determine any effects of supplementation, as iodine status is of known influence on the $\mathrm{FT}_{3}: \mathrm{FT}_{4}$ ratio. Median patient age was 61 years (range 18-90 years). The majority of patients were women $(78 \%)$ and seen in an ambulatory setting (80\%). Thyroid peroxidase antibodies (TPO Abs) or TSH receptor antibodies (TSH R Ab) were measured only when clinically relevant to confirm or exclude suspected thyroid autoimmune disease. In the majority of patients with hypothyroidism in its overt or subclinical form $(n=190)$, the condition was due to thyroid ablative therapy, surgery and/or radioiodine treatment; 53/190 patients (28\%) suffered from thyroid autoimmunity, as evidenced by elevated serum levels of TPO Abs above the reference level. For classification purpose, subclinical thyroid disorders were defined by a TSH value outside reference limits, plus corresponding $\mathrm{FT}_{3}$ and $\mathrm{FT}_{4}$ values within the reference interval. The study was approved by the local ethics committee.

\section{Laboratory methods}

TSH was measured using an enzyme immunoassay (Abbott), with a working range of 0.01-100 mU/l and laboratory-evaluated reference range of $0.4-4.1 \mathrm{mU} / \mathrm{l}$. $\mathrm{FT}_{3}$ and $\mathrm{FT}_{4}$ were determined by non-analogue, twostep immunoassays from the same manufacturer, reference ranges being 2.23-5.36 and 9.5-25 pmol/l respectively. TPO Abs were determined by RIA (reference range $<60 \mathrm{IU} / \mathrm{ml}$ ) and TSH-R Abs by the secondgeneration TRAK assay (reference range $<2 \mathrm{U} /$; BRAHMS, Berlin, Germany). Quality management included standard laboratory evaluation procedures and regular participation in inter-laboratory tests.

\section{Calculations, models and statistical methods}

A physiologically based mathematical model (MiMeNoCoDI model) of thyroid homoeostasis has been previously developed and validated in healthy volunteers and cohorts of patients with defined thyroid disorders, including hypothyroid and hyperthyroid conditions, by one of the authors $(15,16)$. This model has also been made available as an open-source software (SimThyr 3.2 for Mac OS X, Windows and Linux) at sourceforge.net. It allows mapping of the physiological and biochemical interplay to the various parameters involved. With this simulative approach, sensitivity analysis was performed to study the relationship between certain structural parameters such as type 2 deiodinase $\left(\mathrm{D}_{2}\right)$ and thyroid parameters (17). The mathematical equation used for empirical curve fitting was as follows: $\mathrm{TSH}=\mathrm{s} /\left(1+\mathrm{L}_{\mathrm{S}} \times \mathrm{FT}_{4}\right)$, with s referring to maximum secretory capacity and $\mathrm{L}_{\mathrm{S}}$ to the brake constant of non-competitive inhibition at the pituitary site. Theoretical sum activity of peripheral deiodinases $\left(G_{D}\right)$ was calculated from the equation:

$\hat{\mathrm{G}}_{\mathrm{D}}=\frac{\beta_{31}\left(K_{\mathrm{M} 1}+\left(\mathrm{FT}_{4}\right)\right)\left(1+K_{30}(\mathrm{TBG})\right)\left(\mathrm{FT}_{3}\right)}{\alpha_{31}\left(\mathrm{FT}_{4}\right)}$

from equilibrium levels for $\mathrm{FT}_{4}$ and $\mathrm{FT}_{3}$ and from constant parameters for kinetics, plasma proteins and dissociation constants as previously defined and described (17).

Basic descriptive statistics, correlations and linear models were performed using the statistical software packages R 2.15.0 for Mac and Deducer 0.7 with JGR $1.7-10(18,19)$. Kruskal-Wallis rank sum test was used to compare values among groups and analysis of covariance (ANCOVA) was used for comparison of regression lines. For comparison of models, F-statistics and Akaike criteria were applied. In the setting of multiple testing, $P$ values were corrected with the Benjamini-Hochberg method. $P$ values $<0.05$ were considered significant.

\section{Results}

The 1994 patients studied were grouped together according to their treatment. Group 1 comprised untreated subjects, with groups 2-4 subjects on $50-75,100-125$ and $150-200 \mu \mathrm{g} /$ day $\mathrm{L}_{-} \mathrm{T}_{4}$ respectively. Group 5 comprised patients on iodine 
supplementation. Table 1 provides an overview of treatment-related functional states in the five groups. Thyroid parameters differed significantly among groups in the euthyroid state, not in hypothyroidism, and partly in the other conditions shown (Table 1).

The relationships of $\log$ TSH serum levels and peripheral hormone concentrations were analysed over a comparable functional range from the euthyroid to mildly hyperthyroid spectrum defined by $\mathrm{FT}_{4}$ $\geq 9.5 \mathrm{pmol} / \mathrm{l}$ and TSH $>0.01$ and $<100 \mathrm{mU} / \mathrm{l}$ (Fig. 1). The correlations revealed marked differences in the relationships among the groups, particularly between patient groups untreated and on $\mathrm{L}-\mathrm{T}_{4}$.
Gradients of the $\log \mathrm{TSH}-\mathrm{FT}_{3}$ regressions were relatively flat in untreated patients and those taking iodine, but much steeper in $\mathrm{L}-\mathrm{T}_{4}$ treatment (Fig. 1). The $\log$ $\mathrm{TSH}_{-} \mathrm{FT}_{4}$ relationship also displayed significantly higher gradients in treatment groups 3 and 4, but compared with $\log \mathrm{TSH}$ vs $\mathrm{FT}_{3}$, changes were less pronounced (Fig. 1). $\mathrm{G}_{\mathrm{D}}$ was positively correlated with $\log \mathrm{TSH}$ only in untreated subjects (Fig. 1).

Group differences in $\mathrm{TSH}, \mathrm{FT}_{3}, \mathrm{FT}_{4}$ and $\mathrm{G}_{\mathrm{D}}$ were further assessed in defined bands of TSH concentrations (Fig. 2). Over a wide functional range, medians and $95 \%$ confidence interval (CIs) for $\mathrm{FT}_{4}$ and partly $\mathrm{FT}_{3}$ differed significantly from untreated or iodine-treated subjects,

Table 1 Treatment groups and thyroid function states.

\begin{tabular}{|c|c|c|c|c|c|c|}
\hline Thyroid status & Parameter & $\begin{array}{l}\text { Group } 1 \text { no Tx } \\
n=1159\end{array}$ & $\begin{array}{l}\text { Group } 2 \mathrm{~L}-\mathbf{T}_{4} \\
\mathbf{5 0 - 7 5} \mu \mathrm{g} / \text { day } \\
n=254\end{array}$ & $\begin{array}{l}\text { Group } 3 \text { L-T } \\
100-125 \mu \mathrm{g} / \text { day } \\
n=343\end{array}$ & $\begin{array}{l}\text { Group } 4 \mathrm{~L}^{-\mathrm{T}_{4}} \\
150-200 \mu \mathrm{g} / \text { day } \\
n=188\end{array}$ & $\begin{array}{l}\text { Group } 5 \\
\text { iodine } \\
n=50\end{array}$ \\
\hline \multirow[t]{9}{*}{ Hypothyroid } & $n$ & 41 & 15 & 7 & 1 & 0 \\
\hline & \multirow{2}{*}{$\mathrm{FT}_{3}(\mathrm{pmol} / \mathrm{l})$} & 2.25 & 2.41 & 2.09 & 3.67 & - \\
\hline & & $1.49-3.29$ & $1.65-2.91$ & $1.85-2.32$ & - & - \\
\hline & \multirow[t]{2}{*}{$\mathrm{FT}_{4}(\mathrm{pmol} / \mathrm{l})$} & 5.91 & 7.91 & 7.64 & 9.04 & - \\
\hline & & $4.45-8.25$ & $7.01-8.84$ & $6.55-7.93$ & - & - \\
\hline & \multirow[t]{2}{*}{$\mathrm{G}_{\mathrm{D}}(\mathrm{nmol} / \mathrm{s})$} & 35.9 & 28.2 & 24.4 & 37.5 & - \\
\hline & & $27.6-45.0$ & $24.0-35.5$ & $20.9-34.7$ & - & _- \\
\hline & \multirow[t]{2}{*}{$\mathrm{TSH}(\mathrm{mU} / \mathrm{l})$} & 18.6 & 28.3 & 15.3 & 22.8 & - \\
\hline & & $7.24-43.0$ & $9.35-55.48$ & $7.28-38.55$ & - & - \\
\hline \multirow{9}{*}{$\begin{array}{l}\text { Subclinically } \\
\text { hypothyroid }\end{array}$} & $n$ & 54 & 28 & 29 & 6 & 0 \\
\hline & \multirow{2}{*}{$\mathrm{FT}_{3}(\mathrm{pmol} / \mathrm{l})$} & 3.34 & 2.78 & 3.19 & 2.89 & - \\
\hline & & $2.65-3.83$ & $2.30-3.36$ & $2.12-3.82$ & $2.79-3.60$ & - \\
\hline & \multirow[t]{2}{*}{$\mathrm{FT}_{4}{ }^{*}(\mathrm{pmol} / \mathrm{l})$} & 10.9 & 13.1 & 13.9 & 14.9 & - \\
\hline & & $10.4-12.3$ & $11.9-14.1$ & $12.1-15.5$ & $13.8-16.0$ & - \\
\hline & \multirow[t]{2}{*}{$\mathrm{G}_{\mathrm{D}}{ }^{*}(\mathrm{nmol} / \mathrm{s})$} & 27.5 & 19.2 & 18.9 & 16.6 & - \\
\hline & & $19.8-32.4$ & $17.5-21.8$ & $13.8-25.5$ & $16.4-18.7$ & _- \\
\hline & \multirow[t]{2}{*}{$\mathrm{TSH}(\mathrm{mU} / \mathrm{l})$} & 5.62 & 7.24 & 5.87 & 5.32 & - \\
\hline & & $4.88-7.53$ & $5.11-15.3$ & $5.32-9.54$ & $4.49-18.10$ & _- \\
\hline \multirow[t]{9}{*}{ Euthyroid } & $n$ & 731 & 154 & 153 & 31 & 42 \\
\hline & \multirow[t]{2}{*}{$\mathrm{FT}_{3}{ }^{*}(\mathrm{pmol} / \mathrm{l})$} & 3.64 & 3.47 & 3.29 & 3.65 & 3.81 \\
\hline & & $3.13-4.23$ & $2.97-3.94$ & $2.82-3.77$ & $3.13-4.01$ & $3.21-4.18$ \\
\hline & \multirow[t]{2}{*}{$\mathrm{FT}_{4}{ }^{*}(\mathrm{pmol} / \mathrm{l})$} & 13.0 & 14.1 & 16.14 & 17.0 & 13.3 \\
\hline & & $11.8-14.6$ & $12.9-15.8$ & $14.5-18.7$ & $15.4-19.1$ & $13.0-14.4$ \\
\hline & \multirow[t]{2}{*}{$\mathrm{G}_{\mathrm{D}}{ }^{*}(\mathrm{nmol} / \mathrm{s})$} & 25.8 & 21.4 & 18.0 & 19.7 & 26.0 \\
\hline & & $21.8-30.1$ & $18.6-26.3$ & $14.6-22.0$ & $17.1-22.0$ & $22.8-29.0$ \\
\hline & \multirow[t]{2}{*}{$\mathrm{TSH}^{*}(\mathrm{mU} / \mathrm{l})$} & 1.07 & 1.21 & 1.09 & 0.92 & 1.01 \\
\hline & & $0.64-1.64$ & $0.88-2.00$ & $0.75-1.91$ & $0.59-1.87$ & $0.86-1.59$ \\
\hline Subclinically & $n$ & 314 & 55 & 135 & 114 & 8 \\
\hline \multirow[t]{8}{*}{ hyperthyroid } & \multirow[t]{2}{*}{$\mathrm{FT}_{3}{ }^{*}(\mathrm{pmol} / \mathrm{l})$} & 3.77 & 3.56 & 3.93 & 4.07 & 4.13 \\
\hline & & $3.03-4.41$ & $2.99-4.21$ & $3.25-4.43$ & $3.52-4.53$ & $3.63-4.66$ \\
\hline & \multirow[t]{2}{*}{$\mathrm{FT}_{4}^{*}(\mathrm{pmol} / \mathrm{l})$} & 14.7 & 15.4 & 19.4 & 21.5 & 14.5 \\
\hline & & $12.9-16.5$ & $13.4-17.5$ & $17.0-21.6$ & $19.7-23.5$ & $12.6-16.7$ \\
\hline & \multirow[t]{2}{*}{$\mathrm{G}_{\mathrm{D}}{ }^{*}(\mathrm{nmol} / \mathrm{s})$} & 23.5 & 21.7 & 18.3 & 17.4 & 24.2 \\
\hline & & $19.1-27.7$ & $17.7-24.2$ & $16.2-21.3$ & $15.5-19.5$ & $21.7-31.9$ \\
\hline & \multirow[t]{2}{*}{$\mathrm{TSH}(\mathrm{mU} / \mathrm{l})$} & 0.21 & 0.21 & 0.05 & 0.01 & 0.27 \\
\hline & & $0.07-0.31$ & $0.08-0.30$ & $0.01-0.19$ & $0.01-0.06$ & $0.20-0.37$ \\
\hline \multirow[t]{9}{*}{ Hyperthyroid } & $n$ & 19 & 2 & 19 & 36 & 0 \\
\hline & \multirow[t]{2}{*}{$\mathrm{FT}_{3}{ }^{*}(\mathrm{pmol} / \mathrm{l})$} & 7.68 & 4.49 & 4.71 & 4.77 & - \\
\hline & & $4.90-12.0$ & $4.28-4.71$ & $3.93-5.20$ & $4.31-5.54$ & - \\
\hline & \multirow{2}{*}{$\mathrm{FT}_{4}(\mathrm{pmol} / \mathrm{l})$} & 31.8 & 34.5 & 26.5 & 28.4 & _- \\
\hline & & $26.1-38.4$ & $30.8-38.2$ & $25.9-28.3$ & $26.5-29.8$ & - \\
\hline & $\mathrm{G}_{\mathrm{D}}{ }^{*}(\mathrm{nmol} / \mathrm{s})$ & 22.5 & 12.9 & 16.3 & 15.5 & - \\
\hline & & $17.6-30.3$ & $10.9-14.8$ & $13.1-17.8$ & $13.5-17.6$ & - \\
\hline & $\mathrm{TSH}(\mathrm{mU} / \mathrm{l})$ & 0.01 & 0.01 & 0.01 & 0.01 & _- \\
\hline & & $0.01-0.18$ & $0.01-0.01$ & $0.01-0.01$ & $0.01-0.04$ & - \\
\hline
\end{tabular}

$\mathrm{G}_{\mathrm{D}}$, sum activity of peripheral deiodinases. Values indicate median and interquartile range (IQR). An asterisk indicates significant differences $(P<0.05)$ of the parameter among the groups using Kruskal-Wallis rank sum test and $P$ value correction for multiple testing according to Benjamini-Hochberg method. 
as did $\mathrm{G}_{\mathrm{D}}$, because $\mathrm{FT}_{3}$ and $\mathrm{FT}_{4}$ trends were moving in opposite directions (Fig. 2). In the euthyroid TSH range, represented by TSH bands 4 and 5 , medians of $\mathrm{FT}_{3}$ for patients receiving moderate $\mathrm{L}_{\mathrm{L}} \mathrm{T}_{4}$ doses (Groups 2 and 3 ) declined and the lower 95\% CI limits were placed outside the reference range (Fig. 2). Only high $\mathrm{L}-\mathrm{T}_{4}$ doses (Group 4), frequently accompanied by suppressed TSH, placed $\mathrm{FT}_{3}$ values within its reference limits. Patients regarded euthyroid by TSH criteria (TSH bands 4 and 5) would sometimes be classified differently by $\mathrm{FT}_{3}$ and considered hypothyroid in 13/164 (8\%) of the cases in Group 2 on 50-75 $\mu \mathrm{g} / \mathrm{day} \mathrm{L}_{\mathrm{L}} \mathrm{T}_{4}, 18 / 154(12 \%)$ in Group 3 on $100-125 \mu \mathrm{g} /$ day $-\mathrm{T}_{4}$ and $0 / 33(0 \%)$ in Group 4 on 150-200 $\mu \mathrm{g} /$ day L-T $\mathrm{T}_{4}$.
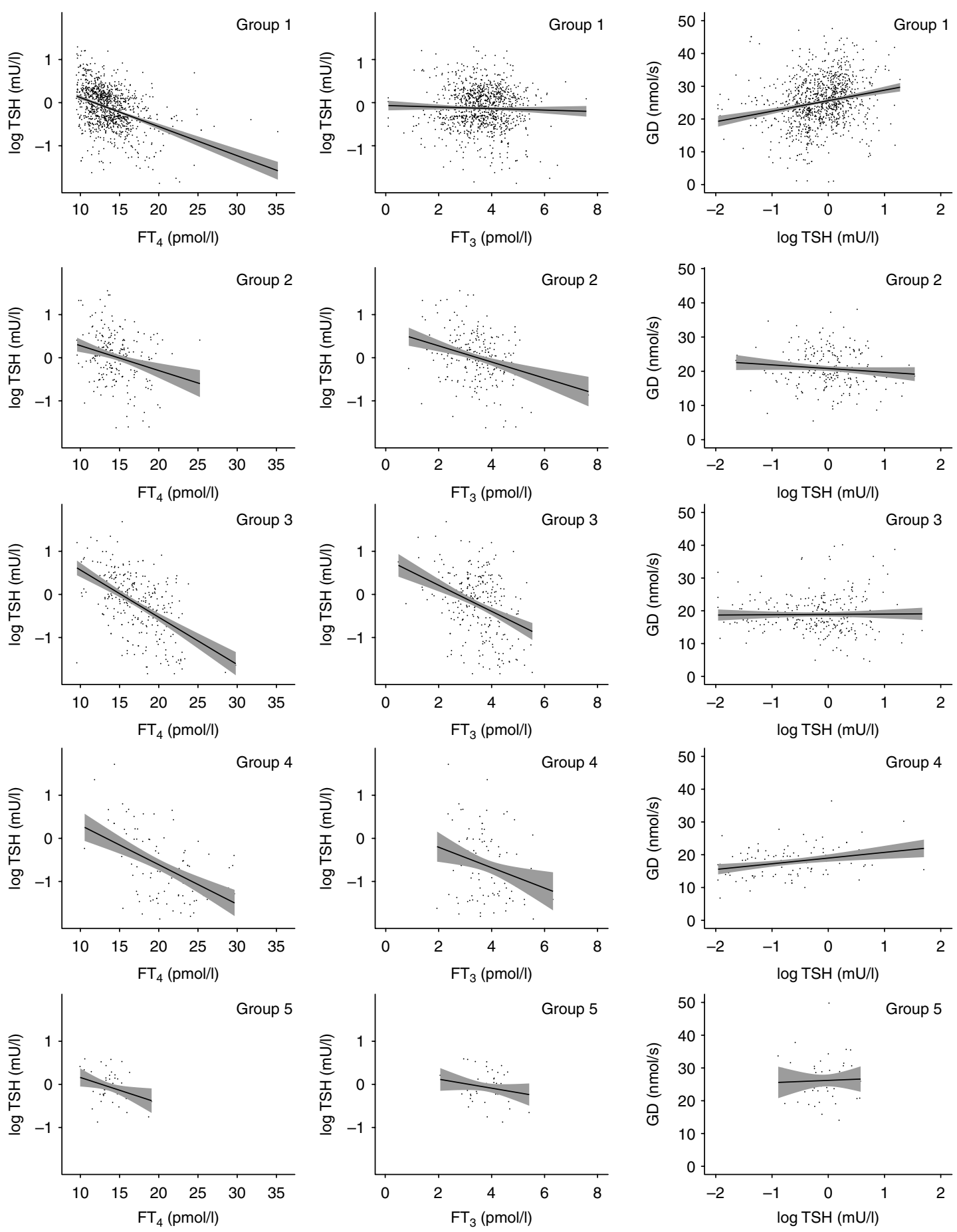

www.eje-online.org 
Theoretical mathematical modelling was performed independently from the analysis of the clinical sample. We have initially assessed the MiMe-NoCoDI model by fitting it to our data sample. This may best be done in an open-loop situation, i.e. in overtly hypothyroid untreated patients, as shown in Fig. 3. For comparison, fitting with the conventional $\log \mathrm{TSH} \mathrm{FT}_{4}$ model is also shown in Fig. 3. As the MiMe-NoCoDI model is based on TSH values rather than their log transformed derivatives, which are commonly applied and used in the latter model, the two models were depicted in terms of TSH vs $\mathrm{FT}_{4}$ (Fig. 3). When statistically comparing the compatibility of the two models with the data (F-statistics and Akaike criteria), their goodness of fit did not significantly alter (Fig. 3).

When applying the MiMe-NoCoDI model, sensitivity analysis revealed that pituitary TSH secretion, in addition to responding to circulating $\mathrm{FT}_{3}$ and $\mathrm{FT}_{4}$ concentrations, is subject to the influence of a variety of structural parameters (Fig. 4, left panel). This importantly includes pituitary $\mathrm{D}_{2}$ (Fig. 4 , left panel). In this model, the divergence of central $\mathrm{T}_{3}$ and peripheral $\mathrm{T}_{3}$ production becomes evident. Increased central $\mathrm{T}_{3}$ by $\mathrm{D}_{2}$ activation suppresses TSH and indirectly (via TSH) reduces $\mathrm{FT}_{4}$ and $\mathrm{FT}_{3}$ production (Fig. 4, right panel).

\section{Discussion}

Originating from a basic understanding of pituitary thyroid feedback, the perspective of the diagnostic role of TSH has shifted in importance and the parameter has been promoted into a separate statistical measure in its own right $(5,6,7,8,9,10,11,12,20)$. Limitations in this approach include analytical issues, genetic variability, uncertainty about the reference range, high ratio of the basic intra-individual to inter-individual variability and considerable natural intra-individual fluctuations (10, 11, 12, 13, 21, 22, 23, 24, 25, 26, 27 , $28,29)$. A lack of correlation with clinical symptom scores occurs particularly in patients with subclinical hypothyroidism (30). However, the implicit assumption of a fixed relationship between peripheral thyroid hormone homoeostasis and the pituitary set point in health and disease has not been seriously questioned. In this study, we show that as a result of the attainment of a hypothyroid state, there is an imbalance and disjoint involving peripheral thyroid hormone homoeostasis and the pituitary set point that persists and is particularly evident under $\mathrm{T}_{4}$ monotherapy. The treatment-related disjoint between peripheral thyroid hormone status and pituitary response became apparent by retrospective correlative analysis of a large clinical sample and was further corroborated by fundamental modelling and independent simulation.

In untreated euthyroid subjects, the gradient of the correlation line relating $\mathrm{FT}_{3}$ and $\log \mathrm{TSH}$ is flat, but in subjects treated by $\mathrm{T}_{4}$ monotherapy, the relationship is different in all cases, the gradient increasing with hormone dosage. This suggests that the balanced relationship between the thyroid hormones themselves and TSH, evident in untreated euthyroids, no longer applies and shows that in monotherapy added increments of $\mathrm{T}_{4}$ are progressively more effective in suppressing TSH production, but simultaneously less effective in restoring $\mathrm{FT}_{3}$. Obviously, this is a consequence of the decreasing ability of thyroid homoeostasis to maintain the normal interrelationships between $\mathrm{T}_{3}$, $\mathrm{T}_{4}$ and $\mathrm{TSH}$.

Hence, the results indicate that the observed disjoint between the thyroid/pituitary $\mathrm{FT}_{4}-\mathrm{TSH}$ feedback mechanism and $\mathrm{T}_{3}$ production noted in hypothyroidism (whether inadequately or untreated) is not fully restored even when sufficient $T_{4}$ is given to regain an apparently euthyroid state. In several cases, this results in a classification mismatch, for example placing $\sim 10 \%$ of patients on moderate $\mathrm{T}_{4}$ doses that are judged euthyroid according to their TSH measurements below the $\mathrm{FT}_{3}$ reference range. Higher $\mathrm{L}_{-} \mathrm{T}_{4}$ doses maintained $\mathrm{FT}_{3}$ within its reference limits, though frequently only in conjunction with suppressed TSH. Gullo et al. (31) have recently reported the same phenomenon in a large homogeneous group of athyreotic patients, whereas Jonklaas et al. (32) reported that total $\mathrm{T}_{3}$ was not

Figure 1 Correlations of log TSH vs $\mathrm{FT}_{4}$, log $\mathrm{TSH}_{\text {vs }} \mathrm{FT}_{3}$ and GD vs $\log \mathrm{TSH}$ in various treatment groups. Group 1: untreated subjects, Groups 2-4: L-T -treated patients with doses of 50-75 $\mu \mathrm{g} /$ day (Group 2), 100-125 $\mu \mathrm{g} /$ day (Group 3) or 150-200 $\mu \mathrm{g} / \mathrm{day}$ (Group 4), Group 5: patients taking iodine supplementation. $P$ values given were corrected for multiple testing by the Benjamini-Hochberg method. Equations of regression lines ( \pm s.E.M.) depicted are as follows: left panels, Group 1: $\log \mathrm{TSH}=-0.069( \pm 0.005){ }^{*} \mathrm{FT}_{4}+0.80( \pm 0.07)$, $r=-0.39, P<0.0001, n=1061$. Group 2: $\log \mathrm{TSH}=-0.058( \pm 0.015){ }^{*} \mathrm{FT}_{4}+0.86( \pm 0.21), r=-0.25, P<0.0001, n=234$. Group 3: $\log \mathrm{TSH}=-0.11( \pm 0.011){ }^{*} \mathrm{FT}_{4}+1.64( \pm 0.19), r=-0.52, P<0.0001, n=284$. Group 4: $\log \mathrm{TSH}=-0.095( \pm 0.016){ }^{*} \mathrm{FT}_{4}+1.23$ ( \pm 0.32$), r=-0.51, P<0.0001, n=109$. Group 5: $\log \mathrm{TSH}=-0.06( \pm 0.025){ }^{*} \mathrm{FT}_{4}+0.75( \pm 0.35), r=-0.32, P=0.02, n=50$. Middle panels, Group 1: $\log \mathrm{TSH}=-0.019( \pm 0.016){ }^{*} \mathrm{FT}_{3}-0.066( \pm 0.06), r=-0.04, P=0.27, n=1061$. Group $2: \log \mathrm{TSH}=-0.18 \pm 0.040$ $\mathrm{FT}_{3}+0.65 \pm 0.14, r=-0.29, P<0.0003, n=234$. Group 3: $\log \mathrm{TSH}=-0.32( \pm 0.044){ }^{*} \mathrm{FT}_{3}+0.87( \pm 0.16), r=-0.40, P<0.0003$, $n=284$. Group 4: $\log \mathrm{TSH}=-0.17( \pm 0.086){ }^{*} \mathrm{FT}_{3}-0.05( \pm 0.33), r=-0.19, P=0.08, n=109$. Group $5: \log \mathrm{TSH}=-0.05 \pm 0.052$ $\mathrm{FT}_{3}+0.12 \pm 0.20, r=-0.13, P=0.37, n=50$. Right panels, Group 1: $\mathrm{G}_{\mathrm{D}}=3.2( \pm 0.44){ }^{*} \log \mathrm{TSH}+25.60( \pm 0.22), r=0.22$, $P=0.0005, n=1061$. Group 2: $\mathrm{G}_{\mathrm{D}}=-1.5( \pm 0.70){ }^{*} \log \mathrm{TSH}+21.86( \pm 0.40), r=-0.14, P=0.06, n=234$. Group 3: $\mathrm{G}_{\mathrm{D}}=-0.10$ $( \pm 0.46){ }^{*} \log \mathrm{TSH}+18.90( \pm 0.36), r=0.01, P=0.83, n=284$. Group 4: $\mathrm{G}_{\mathrm{D}}=1.74( \pm 0.54){ }^{*} \log \mathrm{TSH}+18.98( \pm 0.56), r=0.30$, $P=0.004, n=109$. Group 5: $G_{D}=0.69( \pm 2.68){ }^{*} \log \mathrm{TSH}+26.21( \pm 0.91), r=0.04, P=0.83, n=50$. Slopes were significantly different compared to the untreated Group 1 (ANCOVA), for $\mathrm{FT}_{4}$ in Group $3(P<0.001)$ and Group $4(P<0.03)$, for $\mathrm{FT}_{3}$ in $\mathrm{Group}_{2}(P<0.001)$, Group $3(P<0.001)$ and Group $4(P<0.01)$, for $\mathrm{G}_{\mathrm{D}}$ in Group $2(P<0.001)$, Group $3(P<0.03)$ and Group $4(P<0.001)$. 

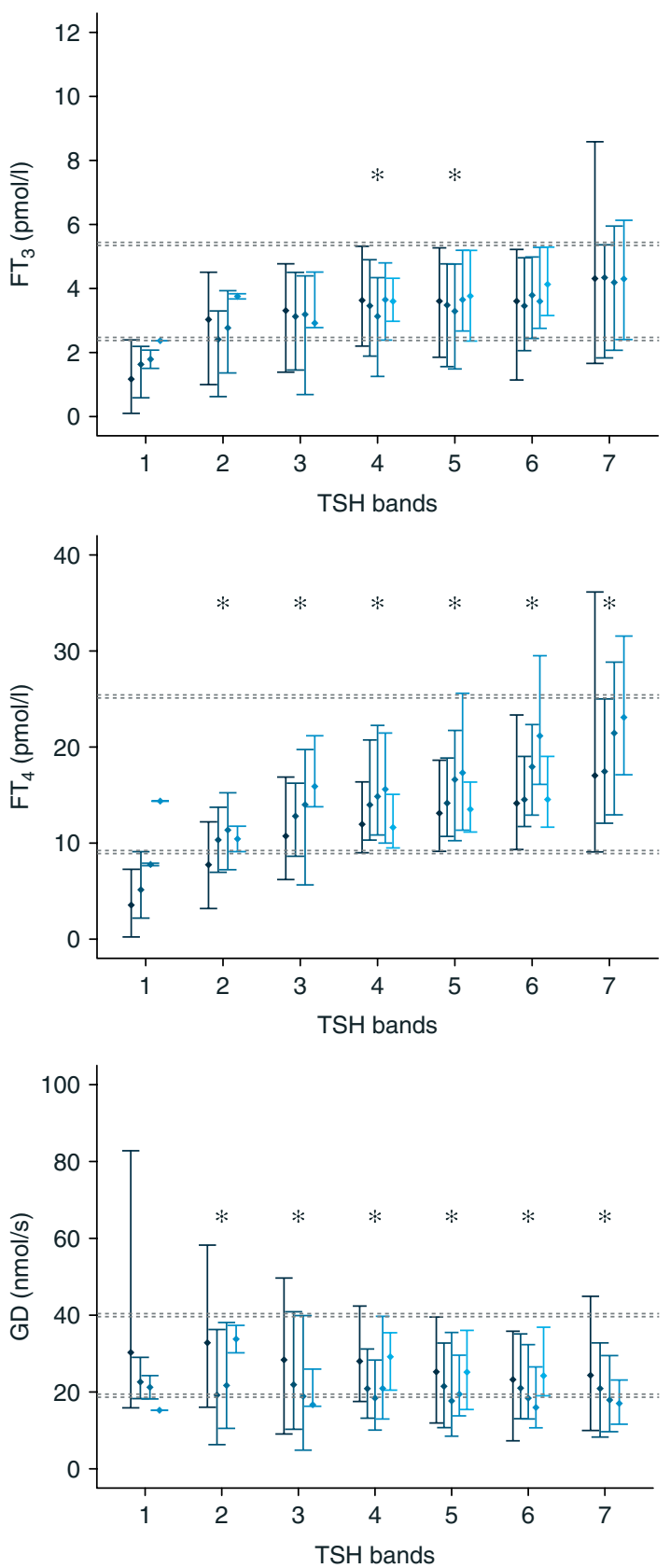

Figure 2 Comparison of medians and 95\% confidence intervals $(95 \% \mathrm{Cl})$ of thyroid parameters in various treatment groups and functional bands defined by TSH values. The TSH bands on the $x$-axis were defined as follows: Band 1: TSH $>50 \mathrm{mU} / \mathrm{l}$, Band 2: TSH 10-50 mU/l, Band 3: TSH 4-10 mU/l, Band 4: TSH 2-4 mU/l, Band 5: TSH 0.4-2 mU/l, Band 6: TSH 0.1-0.4 mU/l and Band 7: TSH $<0.1 \mathrm{mU} / \mathrm{l}$. The error bars $(95 \% \mathrm{Cl})$ depicted in each TSH band refer to Groups 1-5 respectively. Group 1: untreated subjects, Group 2: L-T 4 -treated patients with doses of 50-75 $\mu \mathrm{g} /$ day, Group 3:

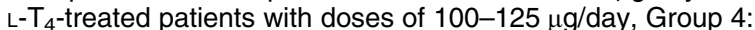

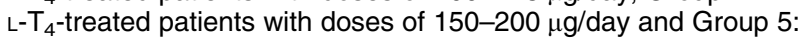
patients taking iodine supplementation. An asterisk indicates the presence of a significant difference $(P<0.05)$ among the groups, as established by Kruskal-Wallis test and Benjamini-Hochberg correction for multiple testing. Full colour version of this figure available via $\mathrm{http} / / / \mathrm{dx}$. doi.org/10.1530/EJE-12-0819. reduced in such patients, but did not study $\mathrm{FT}_{3}$. In contrast, Ito et al. (33) showed that in patients who have undergone thyroidectomy, a moderately TSH-suppressive dose of $\mathrm{L}_{\mathrm{L}} \mathrm{T}_{4}$ is required to postoperatively restore serum $\mathrm{FT}_{3}$ to the preoperative level. Interestingly, earlier studies have also indicated that $\mathrm{L}-\mathrm{T}_{4}$ replacement aiming at a normal serum TSH may not invariably result in an appropriate normalisation of serum $\mathrm{FT}_{3}$ (34).

Additionally, we observed a positive correlation between TSH and $\mathrm{G}_{\mathrm{D}}$ in untreated patients. This could possibly stem from the stimulation by TSH of both type $1\left(\mathrm{D}_{1}\right)$ and type $2\left(\mathrm{D}_{2}\right)$ deiodinases mediated by a signalling process using cAMP $(35,36,37,38$, 39). Interestingly, the correlation was strongest in untreated subjects and impaired in $\mathrm{T}_{4}$-treated patients, suggesting a role of TSH-modulated deiodination within the thyroid gland itself.

The pituitary responds primarily to changes in circulating $\mathrm{FT}_{4}$ by the action of type 2 deiodinase $\left(\mathrm{D}_{2}\right)$ on the local production of $\mathrm{T}_{3}$ (central $\mathrm{T}_{3}$ ) from $\mathrm{T}_{4}(2)$. Circulating $\mathrm{FT}_{3}$ derived mainly from peripheral deiodinase activities has less influence (2). Remarkably, the pituitary retains its ability to respond to increasing $\mathrm{FT}_{4}$ levels in $\mathrm{T}_{4}$-treated subjects, permitting appropriate TSH feedback responses. This may be achieved by a mechanism unique to thyrotrophs, which in contrast to other cells expressing $\mathrm{D}_{2}$, are capable of increasing $\mathrm{D}_{2}$ expression to maintain high $\mathrm{T}_{3}$ production at high $\mathrm{T}_{4}$ concentrations (2). By sensitivity analysis, we have shown that central $\mathrm{T}_{3}$ levels at the pituitary level, as opposed to $\mathrm{T}_{3}$ in the periphery, are up-regulated by the activation of $\mathrm{D}_{2}$. This, in turn, results in suppression of TSH concentrations and, as a further consequence, in a decrease in circulating $\mathrm{FT}_{4}$ and $\mathrm{FT}_{3}$ concentrations. The divergence in the central response from the peripheral equilibrium may explain the observed phenomenon that $\mathrm{FT}_{3}$ serum levels remain disproportionally low even when a supposedly normal TSH has been achieved by means of exogenous $\mathrm{L}^{-\mathrm{T}_{4}}$ administration. This means that the thyroid status and dose adequacy of $\mathrm{T}_{4}$ substitution cannot readily be defined by the putative gold standard TSH in these conditions because TSH concentrations within the accepted reference range may not invariably signal optimum concentrations of the peripherally active hormone $\mathrm{FT}_{3}$.

The clinical findings prompted us to seek independent confirmation on theoretical grounds. To this end, we applied a physiologically based mathematical model of thyroid homoeostasis, which had previously been developed by one of the authors $(15,16)$. Apart from the fact that this model permits simulation of the influence of various structural parameters and sensitivity analysis, which the standard log linear model does not, another advantage is that it does not make a preconceived assumption that the $\mathrm{TSH}-\mathrm{FT}_{4}$ relationship is $\log$ linear but relies on Michaelis Menten kinetics and non-competitive divisive inhibition, thus reflecting the physiological and biochemical interplay of the various 


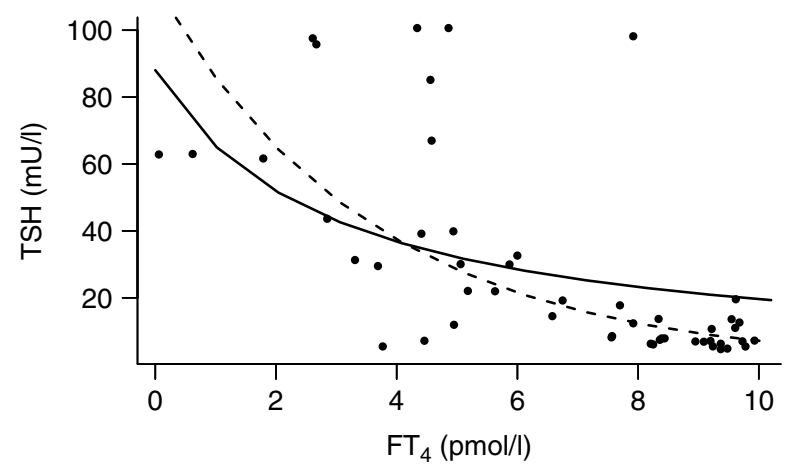

Figure 3 Fit of models to observed data in the subgroup of untreated overtly hypothyroid patients: i) MiMe-NoCoDI model (solid line), ii) log linear standard model (dashed line). The fitting curves to the data points $(n=50)$ were described by the following equations and parameters ( \pm s.E.M.): a) $\mathrm{TSH}=88( \pm 22) /(1+0.35$ $\left.( \pm 0.16){ }^{*} \mathrm{FT}_{4}\right)$ and $\left.\mathrm{b}\right) \log \mathrm{TSH}=-0.12( \pm 0.02){ }^{*} \mathrm{FT}_{4}+2( \pm 0.12)$. For reasons of comparability to $a, b$ is also shown in a nonlogarithmic representation of $\mathrm{TSH}$ vs $\mathrm{FT}_{4}$. Comparisons by F-statistics (sum of residuals 31312 vs $30934, P=N S$ ) and Akaike criteria (AIC 469 vs $466, P=\mathrm{NS}$ ) revealed no significant differences in the goodness of the fits of the two models.

parameters involved (15). The model has previously been validated in a clinical setting (16). It was briefly re-evaluated in the present data sample and provided a reasonably good fit to the data, as did the log linear model. Proof of superiority of one or the other model is a more complex task and beyond the scope of this article, but the question is currently explored in an ongoing prospective trial (NOMOTHETICOS study), the protocol of which has been published (ClinicalTrials.gov NCT01145040, German Clinical Trials Register DRKS00003153, UTN U1111-1122-3273). Sensitivity analysis revealed a dependency of TSH levels on multiple structural parameters of the feedback control system, including the sum activity of pituitary type 2 deiodinase $\left(\mathrm{G}_{\mathrm{D} 2}\right)$, which in turn is modulated by a whole variety of factors (2). TSH-stimulated deiodination, on the other hand, seems to be largely restricted to patients with a functional thyroid gland. Finally, our observation could explain the existence of a subgroup of patients with normal TSH but low $\mathrm{FT}_{3}$ levels.

Although our study may be affected by heterogeneity and its retrospective design, we have been careful to exclude those patients with known problems of assay interpretation. No patient was considered to have a systemic illness of a magnitude likely to initiate a significant 'low $\mathrm{T}_{3}$ syndrome' typical of this condition, though such possibilities must always be envisaged when using $\mathrm{FT}_{3}$ as a diagnostic tool. Although the study group was heterogeneous, relevant comparisons were made in defined TSH segments. While TSH disequilibrium may have been present in some subjects, it does not account for a low $\mathrm{FT}_{3} /$ 'normal' TSH pair because peripheral hormone levels are normalised before TSH in the treatment of hypothyroidism. Apart from acknowledged limitations of a retrospective study design and assay techniques, importantly, there is a second line of independent supportive evidence. Mathematical modelling was found to be in good accord with our empirical findings, supporting a significant disparity between the central $\mathrm{FT}_{3} / \mathrm{TSH}$ and the peripheral $\mathrm{T}_{3}$ under $\mathrm{L}-\mathrm{T}_{4}$.

The described disjoint between $\mathrm{FT}_{4}-\mathrm{TSH}$ feedback and $\mathrm{T}_{3}$ production implies that $\mathrm{T}_{4}$ treatment constitutes a novel compensatory adaptive state of its own and therefore cannot be considered a complete re-enactment and restoration of the previous euthyroid state. This poses the question as to the possible long-term consequences of this disparity and whether thyroid hormone replacement, as it is currently performed, is truly optimal in all cases. Combined $\mathrm{T}_{3} / \mathrm{T}_{4}$ therapy has generally not been found superior in many short-term trials including a meta-analysis $(40,41)$. However, it is possible that certain subjects, e.g. those with limited endogenous thyroid reserve and consecutive hypodeiodination, may benefit, and most studies have used more heterogeneous populations $(40,41)$. Genetic variation, in particular $\mathrm{D}_{2}$ polymorphism, could also play a role $(25,42)$. On the other hand, a TSH value within the reference limits does not guarantee the absence of an adverse clinical outcome (43). This question remains unanswered, but our study encourages the need for further examination of adjunctive $\mathrm{T}_{3}$ therapy in selected patients, as suggested by Biondi \& Wartofsky (40) in a recent review. Further, preferably prospective, studies are required to corroborate and extend these findings: i) to relate the described 'disjoint' to a host of clinically important parameters (e.g. metabolic rate, thermogenesis, lipid profiles and psychological well-being); ii) to elaborate on the possible influence of genomic factors and other influences (such as age, sex, BMI, thyroid volume, disease etiology, iodine intake, selenium status); and iii) to address the remaining methodological concerns by applying equilibrium dialysis or mass spectrometry for hormone measurement (29). Theoretical modelling, as demonstrated here, may prove helpful in guiding the design of adequate clinical trials. There are a few randomised controlled trials or cross-sectional studies that have addressed some of these aspects. Appelhof et al. (44) in a double-blind randomised trial on combined $\mathrm{T}_{3} / \mathrm{T}_{4}$ therapy made the point that satisfaction with study medication was not correlated with either absolute TSH values or with the change in TSH. Saravanan et al. (45) showed that strong correlations between $\mathrm{FT}_{4}$ levels and well-being persisted even when TSH values were within the reference range. To complicate things further, a recent study by Wang et al. (46) suggests that not only may thyroid hormones act independently of TSH but TSH within its reference limits may also exert more direct thyroid hormoneindependent effects, for instance on lipid profiles.

In conclusion, our data suggest that, in order to fully understand the implications of $\mathrm{T}_{4}$ monotherapy in the 

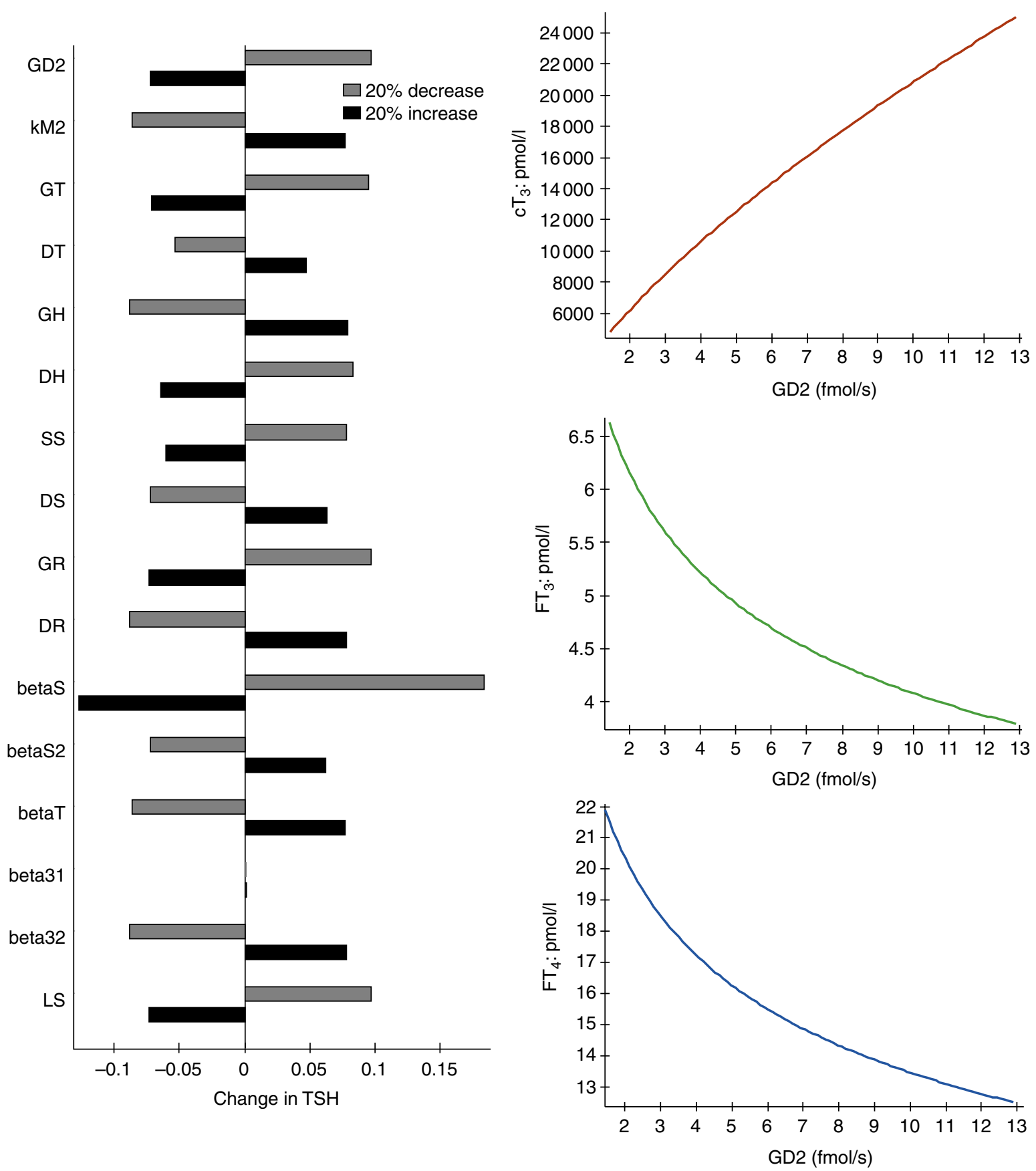

Figure 4 Mathematical model of sensitivity of $\mathrm{TSH}$, central $\mathrm{T}_{3}, \mathrm{FT}_{3}$ and $\mathrm{FT}_{4}$ to changes in structural parameters. According to sensitivity analysis (see Materials and methods section), shown in the left panel, a $20 \%$ variation in various structural parameters' changes, in the absence of any change in circulating $\mathrm{FT}_{3}$ or $\mathrm{FT}_{4}$ concentrations, pituitary TSH secretion by about 5 to $20 \%$. Type 2 deiodinase $\left(D_{2}\right)$ represented by $G_{D 2}$ and $K_{M 2}$ is among the more influential parameters in this respect. In the right panel, the relationships between $G_{D 2}$ activity and central $T_{3}$ and circulating $\mathrm{FT}_{3}$ and $\mathrm{FT}_{4}$ concentrations are shown. Central $\mathrm{T}_{3}$ rises with increasing $\mathrm{GD}_{2}$ activity, thereby suppressing $\mathrm{TSH}$ and, as a consequence, circulating $\mathrm{FT}_{3}$ and $\mathrm{FT}_{4}$ levels decline. $\mathrm{G}_{\mathrm{D} 1}$, maximum activity of type I deiodinase; $\mathrm{K}_{\mathrm{M} 1}$, dissociation constant of $5^{\prime}$-deiodinase I; $\mathrm{G}_{\mathrm{D} 2}$, maximum activity of type II deiodinase; $\mathrm{K}_{\mathrm{M} 2}$, dissociation constant of $5^{\prime}$-deiodinase II; $\mathrm{G}_{\mathrm{T}}$, secretory capacity of thyroid gland; $\mathrm{D}_{\mathrm{T}}$, damping constant $\left(\mathrm{EC}_{50}\right)$ of $\mathrm{TSH}$ at the thyroid gland; $\mathrm{G}_{\mathrm{H}}$, secretory capacity of the pituitary; $\mathrm{D}_{\mathrm{H}}$ damping constant $\left(E_{50}\right)$ of TRH at the pituitary; $S_{S}$, brake constant of TSH ultrashort feedback; $D_{S}, E_{50}$ for TSH at the pituitary; GR, maximum gain of TR $\beta$ receptors; $D_{R}, E_{50}$ for central $T_{3}$, betas, clearance exponent for TSH; betas2, clearance exponent for central TSH; beta $\mathrm{T}_{\mathrm{T}}$, clearance exponent for $\mathrm{T}_{4}$; beta ${ }_{31}$, clearance exponent for $\mathrm{T}_{3 \mathrm{P}}$; beta $\mathrm{b}_{32}$, clearance exponent for central $\mathrm{T}_{3}$; $\mathrm{L}_{\mathrm{S}}$, brake constant (adopted from Dietrich et al. $(15,17)$ ). Full colour version of this figure available via http://dx.doi.org/10.1530/EJE-12-0819. 
hypothyroid patient, the normalisation of $\mathrm{T}_{3}$ production for maintenance of the metabolic processes should be considered to be equally as relevant as the control of the mechanisms of $\mathrm{T}_{4}-\mathrm{TSH}$ feedback that currently dominate functional diagnostic procedures. The two cannot be regarded as equivalent owing to their treatmentrelated disparity of response. This challenges the role of TSH as an exclusive standard in assessing dose adequacy in thyroid hormone replacement and invites further study.

\section{Declaration of interest}

The authors declare that there is no conflict of interest that could be perceived as prejudicing the impartiality of the research reported.

\section{Funding}

This research did not receive any specific grant from any funding agency in the public, commercial or not-for-profit sector.

\section{Acknowledgements}

The authors wish to thank Walter Eckl for technical assistance with the data set.

\section{References}

1 Braverman LE \& Utiger RD. Introduction to thyrotoxicosis. In The Werner and Ingbar's Thyroid, 6th edn, ch 30, pp 645-647. Eds LE Braverman \& RD Utiger. Philadelphia: J.B. Lippincott Company, 1995.

2 Gereben B, Zavacki AM, Ribich S, Kim BW, Huang SA, Simonides WS, Zeold A \& Bianco AC. Cellular and molecular basis of deiodinase-regulated thyroid hormone signaling. Endocrine Reviews 200829 898-938. (doi:10.1210/er.2008-0019)

3 Arrojo E, Drigo R \& Bianco AC. Type 2 deiodinase at the crossroads of thyroid hormone action. International Journal of Biochemistry $\mathcal{E}$ Cell Biology 201143 1432-1441. (doi:10.1016/j.biocel.2011. 05.016)

4 Pilo A, Iervasi G, Vitek F, Ferdeghini M, Cazzuola F \& Bianchi R. Thyroidal and peripheral production of $3,5,3^{\prime}$-triiodothyronine in humans by multicompartmental analysis. American Journal of Physiology 1990258 E715-E726.

5 Demers LM \& Spencer CA. Thyrotropin/thyroid stimulating hormone (TSH) measurement. Thyroid 200313 33-44. (doi:10. 1089/105072503321087015)

6 Flynn RWV, Macdonald TM, Jung RT, Morris AD \& Leese GP. Mortality and vascular outcomes in patients treated for thyroid dysfunction. Journal of Clinical Endocrinology and Metabolism 2006 91 2159-2164. (doi:10.1210/jc.2005-1833)

7 Völzke H, Schwahn C, Wallaschofski H \& Dörr M. Review: the association of thyroid dysfunction with all-cause and circulatory mortality: is there a causal relationship? Journal of Clinical Endocrinology and Metabolism $2007 \quad 92 \quad 2421-2429$. (doi:10.1210/jc.2007-0179)

8 Waring AC, Harrison S, Samuels MH, Ensrud KE, Le Blanc ES, Hoffman AR, Orwoll E, Fink HA, Barrett-Connor E \& Bauer DC. Thyroid function and mortality in older men: a prospective study. Journal of Clinical Endocrinology and Metabolism 201297 862-870. (doi:10.1210/jc.2011-2684)

9 Weiss IA, Bloomgarden N \& Frishman WH. Subclinical hypothyroidism and cardiovascular risk: recommendations for treatment. Cardiology in Review 201119 291-299. (doi:10.1097/CRD. Ob013e318227df87)
10 Dickey RA, Wartofsky L \& Feld S. Optimal thyrotropin level: normal ranges and reference intervals are not equivalent. Thyroid 200515 1035-1039. (doi:10.1089/thy.2005.15.1035)

11 Laurberg P, Andersen S, Carlé A, Karmisholt J, Knudsen N \& Pedersen IB. The TSH upper reference limit: where are we at? Nature Reviews. Endocrinology 20117 232-239. (doi:10.1038/ nrendo.2011.13)

12 Surks MI, Goswami G \& Daniels GH. The thyrotropin reference range should remain unchanged. Journal of Clinical Endocrinology and Metabolism $2005 \quad 90$ 5489-5496. (doi:10.1210/jc.2005-0170)

13 Andersen S, Pedersen KM, Bruun NH \& Laurberg P. Narrow individual variations in serum $\mathrm{T}(4)$ and $\mathrm{T}(3)$ in normal subjects: a clue to the understanding of subclinical thyroid disease. Journal of Clinical Endocrinology and Metabolism 200287 1068-1072. (doi:10.1210/jc.87.3.1068)

14 Hoermann R, Eckl W, Hoermann C \& Larisch R. Complex relationship between free thyroxine and TSH in the regulation of thyroid function. European Journal of Endocrinology 2010162 1123-1129. (doi:10.1530/EJE-10-0106)

15 Dietrich JW, Tesche A, Pickardt CR \& Mitzdorf U. Thyrotropic feedback control: evidence for an additional ultrashort feedback loop from fractal analysis. Cybernetics and Systems $2004 \mathbf{3 5}$ 315-331. (doi:10.1080/01969720490443354)

16 Dietrich JW. Der Hypophysen-Schilddrsen-Regelkreis. Entwicklung und klinische Anwendung eines nichtlinearen Modells. In Spektrum Medizinische Forschung, pp 1-188. Ed F Schardt. Berlin: Logos Verlag, 2002.

17 Dietrich JW, Stachon A, Antic B, Klein HH \& Hering S. The AQUA-FONTIS study: protocol of a multidisciplinary, crosssectional and prospective longitudinal study for developing standardized diagnostics and classification of non-thyroidal illness syndrome. BMC Endocrine Disorders 20088 13. (doi:10.1186/ 1472-6823-8-13)

18 R Development. Core Team R: A Language and Environment for Statistical Computing. R Foundation for Statistical Computing 2012 ISBN 3-900051-07-0. Available from http:// cran.r-project.org.

19 Fellows I. Deducer: Deducer R package version 0.7-0. 2012. Available from http://cran.r-project.org.

20 Larsen PR. Thyroid-pituitary interaction: feedback regulation of thyrotropin secretion by thyroid hormones. New England Journal of Medicine 1982306 23-32. (doi:10.1056/NEJM1982010730 60107)

21 Andersen S, Bruun NH, Pedersen KM \& Laurberg P. Biologic variation is important for interpretation of thyroid function tests. Thyroid 200313 1069-1078. (doi:10.1089/105072503770 867237)

22 Aoki Y, Belin RM, Clickner R, Jeffries R, Phillips L \& Mahaffey KR. Serum TSH and total $\mathrm{T}_{4}$ in the United States population and their association with participant characteristics: National Health and Nutrition Examination Survey (NHANES 1999-2002). Thyroid 200717 1211-1223. (doi:10.1089/thy.2006.0235)

23 Collet T-H, Gussekloo J, Bauer DC, Elzen den WPJ, Cappola AR, Balmer P, Iervasi G, Asvold BO, Sgarbi JA, Völzke H et al. Subclinical hyperthyroidism and the risk of coronary heart disease and mortality. Archives of Internal Medicine 2012172 799-809. (doi:10.1001/archinternmed.2012.402)

24 Hamilton TE, Davis S, Onstad L \& Kopecky KJ. Thyrotropin levels in a population with no clinical, autoantibody, or ultrasonographic evidence of thyroid disease: implications for the diagnosis of subclinical hypothyroidism. Journal of Clinical Endocrinology and Metabolism 200893 1224-1230. (doi:10.1210/jc.2006-2300)

25 Hoftijzer HC, Heemstra KA, Visser TJ, le Cessie S, Peeters RP, Corssmit EPM \& Smit JWA. The type 2 deiodinase ORFa-Gly3Asp polymorphism (rs12885300) influences the set point of the hypothalamus-pituitary-thyroid axis in patients treated for differentiated thyroid carcinoma. Journal of Clinical Endocrinology and Metabolism 201196 E1527-E1533. (doi:10.1210/ jc.2011-0235) 
26 Hollowell JG, Staehling NW, Flanders WD, Hannon WH, Gunter EW, Spencer CA \& Braverman LE. Serum TSH, T(4), and thyroid antibodies in the United States population (1988 to 1994): National Health and Nutrition Examination Survey (NHANES III). Journal of Clinical Endocrinology and Metabolism $2002 \mathbf{8 7}$ 489-499. (doi:10.1210/jc.87.2.489)

27 Over R, Mannan S, Nsouli-Maktabi H, Burman KD \& Jonklaas J. Age and the thyrotropin response to hypothyroxinemia. Journal of Clinical Endocrinology and Metabolism 201095 3675-3683. (doi:10.1210/jc.2010-0281)

28 Spencer CA, Hollowell JG, Kazarosyan M \& Braverman LE. National Health and Nutrition Examination Survey III thyroidstimulating hormone (TSH)-thyroperoxidase antibody relationships demonstrate that TSH upper reference limits may be skewed by occult thyroid dysfunction. Journal of Clinical Endocrinology and Metabolism 200792 4236-4240. (doi:10.1210/jc.2007-0287)

29 van Deventer HE, Mendu DR, Remaley AT \& Soldin SJ. Inverse loglinear relationship between thyroid-stimulating hormone and free thyroxine measured by direct analog immunoassay and tandem mass spectrometry. Clinical Chemistry $2011 \quad \mathbf{5 7} \quad 122-127$. (doi:10.1373/clinchem.2010.154088)

30 Karmisholt J, Andersen S \& Laurberg P. Variation in thyroid function tests in patients with stable untreated subclinical hypothyroidism. Thyroid 200818 303-308. (doi:10.1089/thy. 2007.0241)

31 Gullo D, Latina A, Frasca F, Le Moli R, Pellegriti G \& Vigneri R. Levothyroxine monotherapy cannot guarantee euthyroidism in all athyreotic patients. PLOS ONE 20116 e22552. (doi:10.1371/ journal.pone.0022552)

32 Jonklaas J, Davidson B, Bhagat S \& Soldin SJ. Triiodothyronine levels in athyreotic individuals during levothyroxine therapy. Journal of the American Medical Association 2008299 769-777. (doi:10.1001/jama.299.7.769)

33 Ito M, Miyauchi A, Morita S, Kudo T, Nishihara E, Kihara M, Takamura Y, Ito Y, Kobayashi K, Miya A et al. TSH-suppressive doses of levothyroxine are required to achieve preoperative native serum triiodothyronine levels in patients who have undergone total thyroidectomy. European Journal of Endocrinology 2012. (doi:10.1530/EJE-11-1029)

34 Woeber KA. Levothyroxine therapy and serum free thyroxine and free triiodothyronine concentrations. Journal of Endocrinological Investigation 200225 106-109.

35 Larsen PR \& Berry MJ. Nutritional and hormonal regulation of thyroid hormone deiodinases. Annual Review of Nutrition 199515 323-352. (doi:10.1146/annurev.nu.15.070195.001543)

36 Bianco AC, Maia AL, da Silva WS \& Christoffolete MA. Adaptive activation of thyroid hormone and energy expenditure. Bioscience Reports 200525 191-208. (doi:10.1007/s10540-005-2885-6)

37 Maia AL, Goemann IM, Meyer ELS \& Wajner SM. Type 1 iodothyronine deiodinase in human physiology and disease: deiodinases: the balance of thyroid hormone. Journal of Endocrinology 2011209 283-297. (doi:10.1530/JOE-10-0481)

38 Murakami M, Kamiya Y, Morimura T, Araki O, Imamura M, Ogiwara T, Mizuma H \& Mori M. Thyrotropin receptors in brown adipose tissue: thyrotropin stimulates type II iodothyronine deiodinase and uncoupling protein-1 in brown adipocytes. Endocrinology 2001142 1195-1201. (doi:10.1210/en.142.3.1195)

39 Nakao N, Ono H, Yamamura T, Anraku T, Takagi T, Higashi K, Yasuo S, Katou Y, Kageyama S, Uno Y et al. Thyrotrophin in the pars tuberalis triggers photoperiodic response. Nature $2008 \mathbf{4 5 2}$ 317-322. (doi:10.1038/nature06738)

40 Biondi $\mathrm{B} \&$ Wartofsky L. Combination treatment with $\mathrm{T}_{4}$ and $\mathrm{T}_{3}$ : toward personalized replacement therapy in hypothyroidism? Journal of Clinical Endocrinology and Metabolism 201297 2256-2271. (doi:10.1210/jc.2011-3399)

41 Grozinsky-Glasberg S, Fraser A, Nahshoni E, Weizman A \& Leibovici L. Thyroxine-triiodothyronine combination therapy versus thyroxine monotherapy for clinical hypothyroidism: meta-analysis of randomized controlled trials. Journal of Clinical Endocrinology and Metabolism $2006 \quad 91 \quad 2592-2599$. (doi:10.1210/jc.2006-0448)

42 Panicker V, Saravanan P, Vaidya B, Evans J, Hattersley AT, Frayling TM \& Dayan CM. Common variation in the DIO2 gene predicts baseline psychological well-being and response to combination thyroxine plus triiodothyronine therapy in hypothyroid patients. Journal of Clinical Endocrinology and Metabolism 2009 94 1623-1629. (doi:10.1210/jc.2008-1301)

43 Heeringa J, Hoogendoorn EH, van der Deure WM, Hofman A, Peeters RP, Hop WCJ, Heijer den M, Visser TJ \& Witteman JCM. High-normal thyroid function and risk of atrial fibrillation: the Rotterdam study. Archives of Internal Medicine $2008 \mathbf{1 6 8}$ 2219-2224. (doi:10.1001/archinte.168.20.2219)

44 Appelhof BC, Fliers E, Wekking EM, Schene AH, Huyser J, Tijssen JGP, Endert E, van Weert HCPM \& Wiersinga WM. Combined therapy with levothyroxine and liothyronine in two ratios, compared with levothyroxine monotherapy in primary hypothyroidism: a double-blind, randomized, controlled clinical trial. Journal of Clinical Endocrinology and Metabolism 200590 2666-2674. (doi:10.1210/jc.2004-2111)

45 Saravanan P, Visser TJ \& Dayan CM. Psychological well-being correlates with free thyroxine but not free 3,5,3'-triiodothyronine levels in patients on thyroid hormone replacement. Journal of Clinical Endocrinology and Metabolism 200691 3389-3393. (doi:10.1210/jc.2006-0414)

46 Wang F, Tan Y, Wang C, Zhang X, Zhao Y, Song X, Zhang B, Guan Q, Xu J, Zhang J et al. Thyroid-stimulating hormone levels within the reference range are associated with serum lipid profiles independent of thyroid hormones. Journal of Clinical Endocrinology and Metabolism 201297 2724-2731. (doi:10. 1210/jc.2012-1133)

Received 17 September 2012

Revised version received 9 November 2012

Accepted 26 November 2012 